\title{
Konus Seviyesinde Gelișen 5 Schwannoma Olgusunda Total Rezeksiyon ve Nörolojik Defisitin Önlemesinde Nöromonitarizayonun Yeri
}

\author{
Total Removal in 5 Cases with Conus Medullary Tumor and Significance of Neuromonitorization to Prevent \\ Neurological Deficit
}

Hakan Özalp', Onur Özgüral², İhsan Doğan², Melih Bozkurt²

'Acıbadem Hastanesi, Beyin ve Sinir Cerrahi Anabilim Dall, Ankara,
Türkiye
2Ankara Üniversitesi, Tıp Fakültesi, Beyin ve Sinir Cerrahi Anabilim Dall, Ankara, Türkiye
Geliș tarihi : 09.10.2014 • Kabul tarihi: 19.11.2014

Iletișim

Uz Dr. Hakan Özalp

GSM: 05307616434

E-posta: hsozalp@gmail.com

Acıbadem Ankara Hastanesi Beyin ve Sinir Cerrahisi AD.

Turan Günes Bulvarı 630. Sokak No: 6 Or-An, Cankaya

Amaç: Sinir kılıfı tümörleri spinal tümörler içinde en sık rastlanılan tümörlendendir ve bunlar içinde en çok schwannomlar ve nörofibrom görülmektedir. Bulundukları lokalizasyona göre ciddi morbidite yapabilirler ve total çıkarılmaları kür sağlar. Biz bu yazımızda konus medullaris seviyesinde yerleșen olgularımızı ve operasyonlarda total eksizyonun önemi ve bunda nöromonitarizasyonun faydalarını tartıștık.

Materyal Metod: 2012-2014 yılları arasında Ankara Üniversitesi Tıp Fakültesi Hastanesi Beyin ve Sinir Cerrahisine bașvuran toplam 5 konus medullaris kitlesi bulunan hasta nöromonitorizasyon kullanılarak opere edildi.

Olgu: 5 hasta da konus medullaris tümörü mevcuttu. Hastaların üçünde bel ve bacak ağrısı mevcuttu. Hastalardan ikisinde, bu iki olguda nüks-rezidü vakalardı, nörolojik defisit mevcuttu. Bunlardan birinde de couda equina sendromu gelișmiști. Bu olguların ikisi anterolateral üçü posterior yolla opere edildi. Ameliyatların tümünde elektromonitörizayon yapıldı. Postoperatif hiçbir hastada nörolojik kötüleșme izlenmedi. 4 hasta da total rezeksiyon, 1 hastada subtotal rezeksiyon sağlandı.

Tartıșma-Sonuç: Uygun cerrahi yöntemin seçilmesi, uygun mikrocerrahi yöntemler ve nöromonitarizasyonun kullanılması nüks-rezidü vakalarda bile total rezeksiyona imkan sağlamıș ve nörolojik defisit gelișmesini önlemiștir. Böylece, konus medullaris shwannomlarında temel mikrocerrahi prensiplerin yanısıra nöromonitorizasyon kullanılması postoperatif morbiditeyi azaltmakta ve total eksizyon kur sağlayabilmektedir.

Anahtar Sözcükler: Schwannom, konuş medullaris, elektromonitörizasyon

Aim: Nerve sheath tumors are the most common tumors among the spinal tumors and mostly seen as schwannom and neurofibroma. They may cause serious morbidity by the localization and total excision provides cure. In this article, we present the cases who have conus medullary tumors, to emphasize the total excision of tumor and to discuss the benefits of neuromonitorization.

Material and Method: 5 patients who had conus medullary tumors admitted to department of Neurosurgery Ankara University Faculty of Medicine was operated by adjunct of neuromonitorization between 2012-2014.

Case: All the patients have conus medullary tumors. Three of them had lumbalgia and limb pain. Two of were recurrent tumors that had neurological deficit. One of these two patients had cauda equina syndrome. Three of them was operated by the anterolateral and rest of cases were operated by the posterior approach. Electroneuromonitorization was used for all cases. Postoperatively, there was no additional neurological deficit. Four of patients achieved totally and 1 was subtotally excision.

Discussion-Result: To choose for optimal approach and microsurgical tecniques and apply to neuromonitorization provides totally excision and prevent neurological impairment even in recurrent cases. Thus, in conus medullary schwannomas, to apply essential microsurgical methods with neuromonitorization can reduce postoperatively morbidity and totally removal of mass may provide cure.

Key Words: Schwannoma, medullary conus, electromonitorization

Spinal tümörler nadir görülmelerine rağmen bulundukları lokalizasyonlara bağlı olarak ciddi morbidite nedeni olabilirler. Ekstremitelerde parazi, pleji, idrar ve gayta inkontinans1 yapabilirler. Intradural ekstra medüller tümörlerin büyük kısmını, meningiomalar, sinir kılıfi tümörleri ve metastazlar oluşturur (1). Sinir k1lıfi tümörlerini schwannom, nörofibrom ve ganglionörom oluşturur. Bunlar içinde en sık schwannomlar görülür. En sık 4. dekadda görülürler ve en sık servikal ve lomber bölgeyi tutarlar. Bu tümörlerin yarisindan fazlas intradural ekstramedüllerdir (1). Klinikte gece artan ağrilar tipiktir. 
Genellikle iyi huylu tümörler olup, nörofibromlarda \%4-11 sarkomatöz dejenerasyon görülür (2). Spinal kord genelde L1-2 seviyesinde sonlanir ve bu bölgesine konus medullaris denir. $\mathrm{Bu}$ bölgenin tümörlerinde diğer nörolojik bulgularla birlikte, idrargayta inkontinans1, impotans görülebilir. Diğer nörolojik bulguların olmadığı bu vakalarda konus medullarise yerleşen tümörler diğer organ rahatsızlıklarına bağlanarak atlanabilir (3). Spinal schwannomlar ise yetişkindeki spinal tümörlerin yaklaş1k \%25 ini kapsar (4,5,6 ). Birçok schwannom karakteristik olarak sert kapsüllü ve Schwann hücrelerinden oluşmaktadır (6). Kitlenin total eksizyonu genellikle cerrahi hedefe ulaşmakta yeterlidir (7).

Biz bu yazımızda konus medullaris seviyesinde yerleşen olgularımızı ve operasyonlarda total eksizyonun önemi ve bunda nöromonitörizasyonun faydalarını tartıştık.

\section{OLGULAR}

Olgu-1: 21 Yaşında, erkek. 3 yıldır ağn1 kesicilere dirençli bel ve sol bacak ağrisı mevcuttu. Nörolojik muayenede lateralizayon veren motor ve duyu defisiti yoktu. Nöromonitörizasyon eşliğinde anterior girişimle total tümör eksizyonu yapild. Postoperatif dönemde nörolojik defisit gelişmedi.

Olgu-2: 53 yaşında erkek hastanın, 4 yıldır bel ve bacaklarında mevcut olan ağn1 şikayeti bulunmaktayd. Lateralizasyon veren motor ve duyu defisiti yoktu. Posteriordan elektromonitörizasyon eşliğinde total tümör eksizyonu yapıldı. Peroperatif elektropotansiyellerde düşme nedeniyle subtotal eksizyon yapildı. Postoperatif nörolojik defisit.

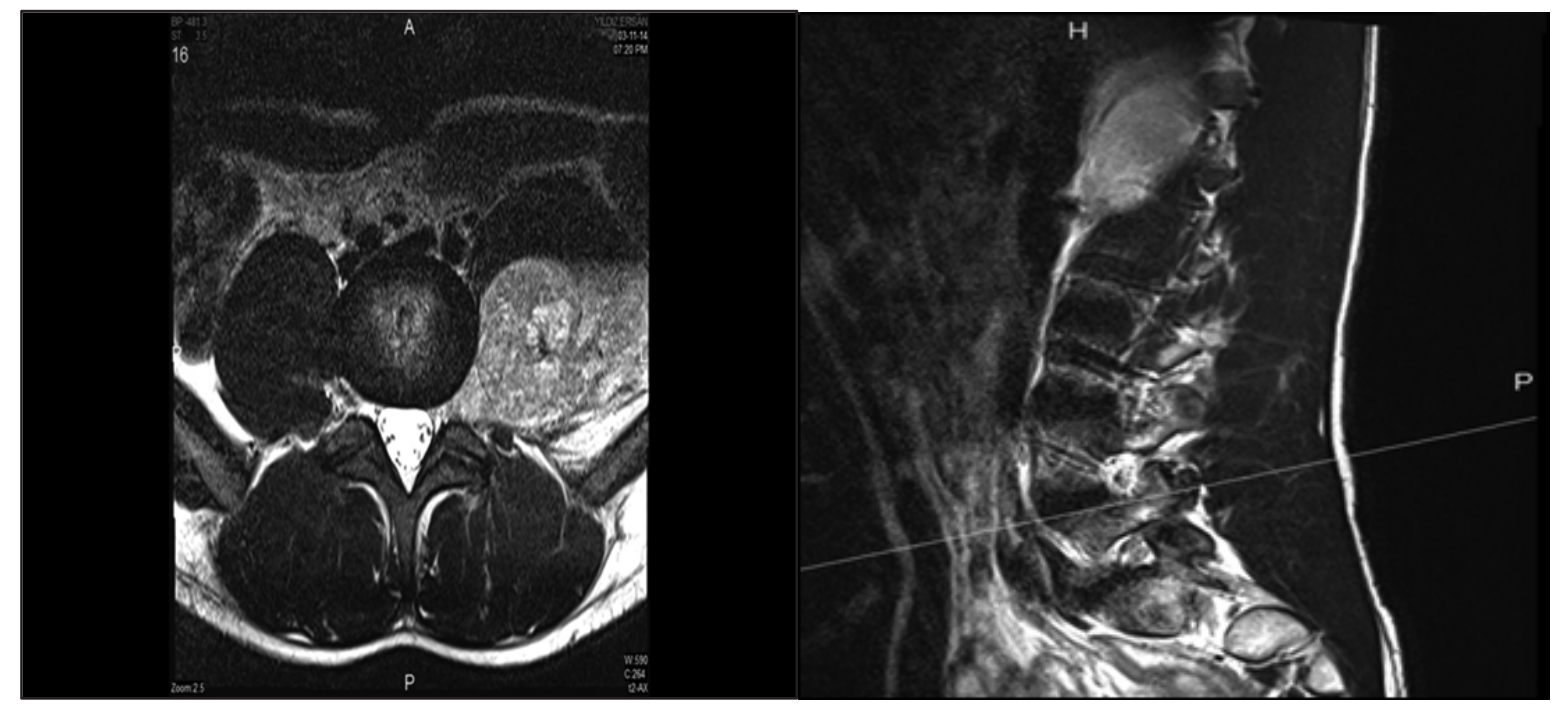

Şekil 1: 21 Yaşında, erkek. 3 yıldır ağrı kesicilere dirençli bel ve sol bacak ağrısı mevcut nörolojik muayenede lateralizayon veren motor ve duyu defisiti yoktu

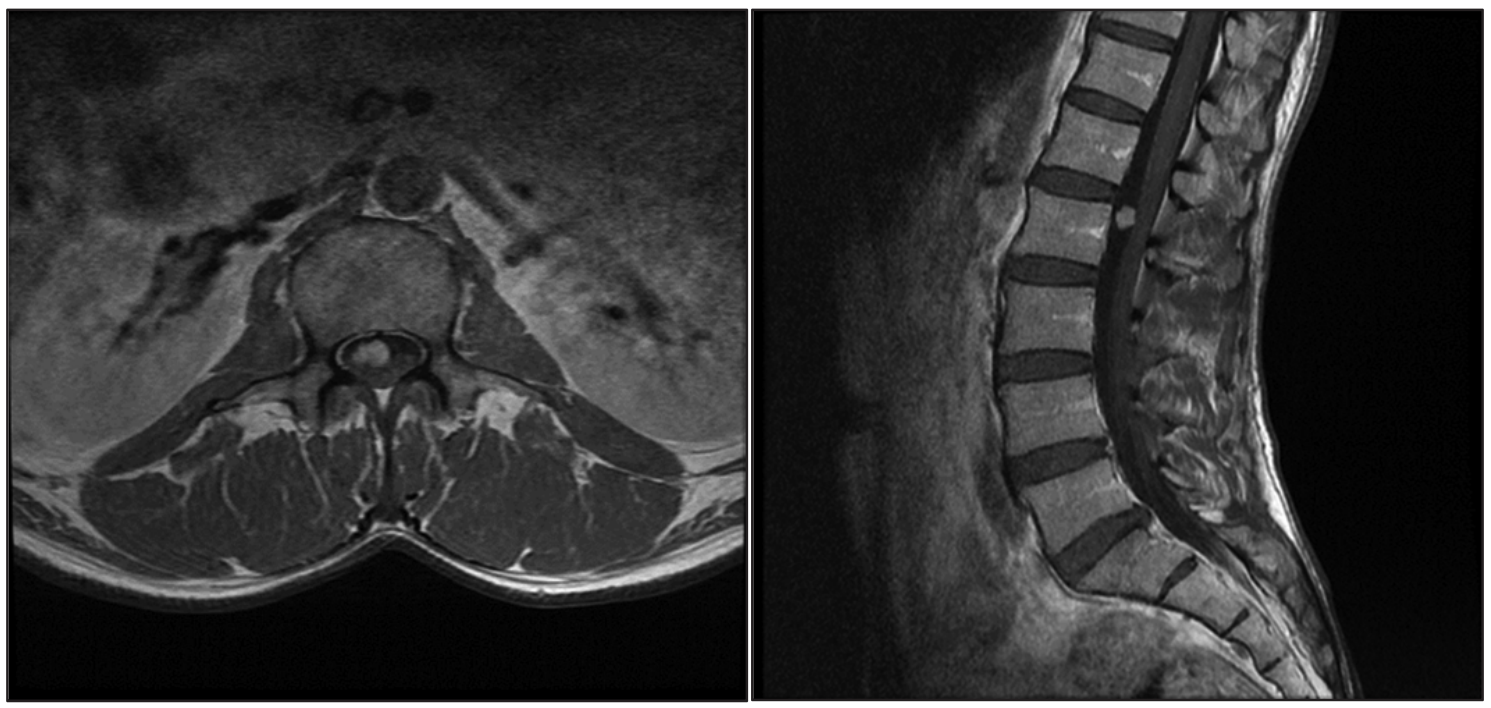

Şekil 2: 53 yaşında erkek, bel ve bacaklarda ağrı şikayeti 4 yıldır mevcut idi. Lateralizasyon veren motor ve duyu defisiti yoktu. 
Olgu-3: 54 yaşında erkek hasta 3 yildır sağ bacakta ağrı ve güç kaybı şikayeti mevcuttu. Hastanin hikayesinde bir y1l öncesubtotal tümör eksizyon mevcuttu. Nörolojik muayenesinde sağ bacak 3-4/5 hemiparetik olarak saptand. Anterolateral yaklaşımla nöromonitörizasyon eşliğinde total tümör eksizyonu yapıldı. Postoperatif ek nörolojik defisiti gelişmedi.

Olgu-4: 31 yaşında bayan hasta 5 ylldır bel ve bacaklarda ağrı şikayetiyle başvurdu. Lateralizasyon veren motor ve duyu defisiti yoktu. Posterior yaklaşımla ve elektromonitörizasyon eşliğinde total total tümör eksizyonu yapıldı. Postoperatif nörolojik defisit saptanmadi.

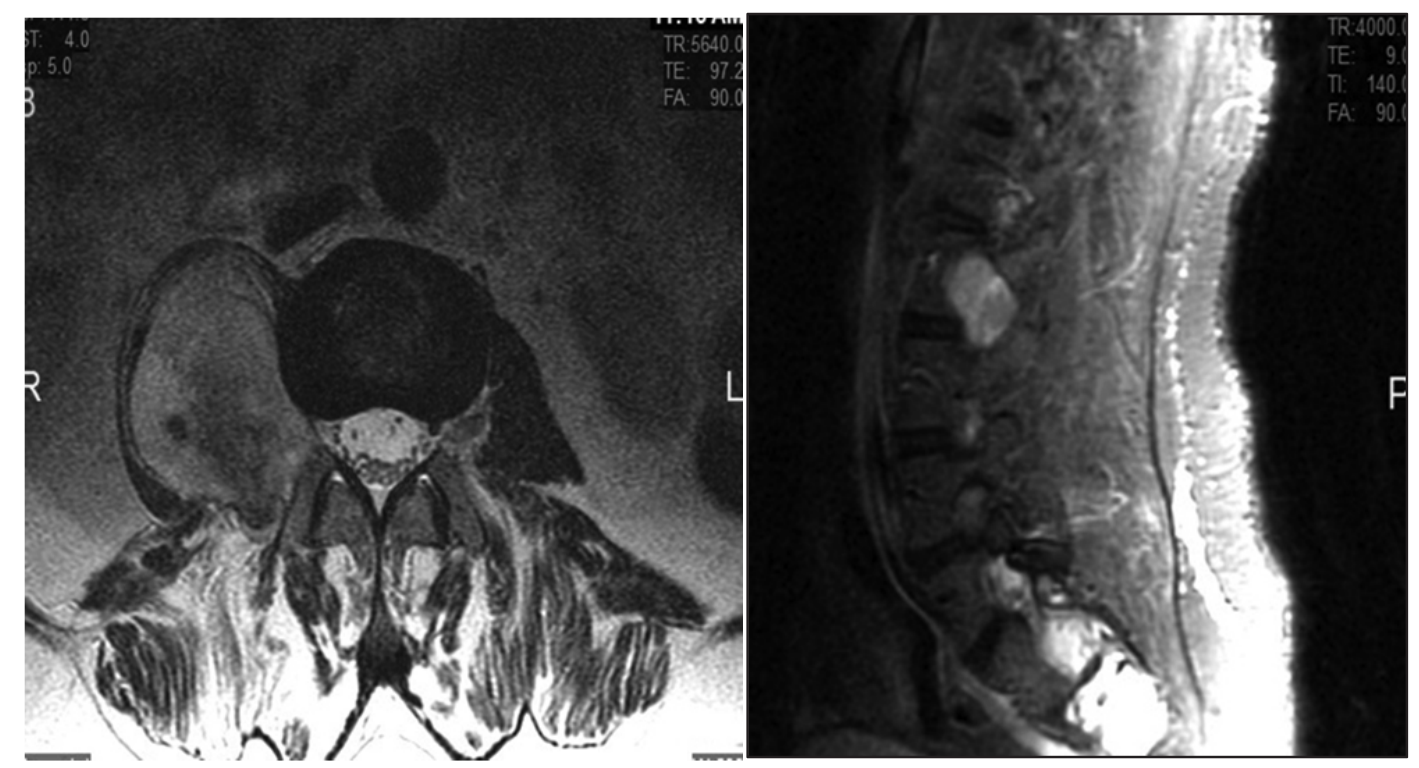

Şekil 3: 54 yaşında erkek hasta 3 yıldır sağ bacakta ağrı ve güç kaybı şikayeti mevcut idi. Hastanın hikayesinde bir yıl önce subtotal tümör eksizyon mevcuttu.

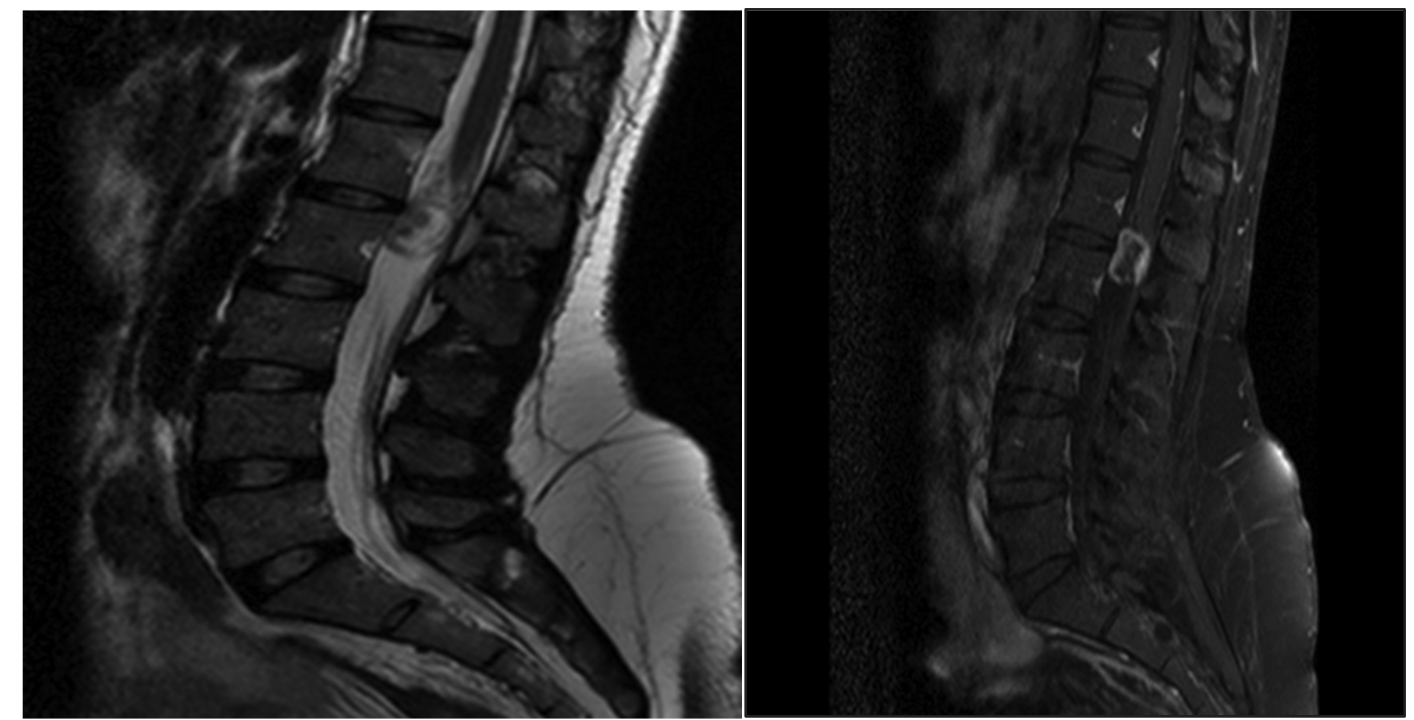

Şekil 4: 31 yaşında bayan hasta 5 yıldır bel ve bacaklarda ağrı şikayetiyle başvurdu. Lateralizasyon veren motor ve duyu defisiti yok idi.

Olgu-5: 42 yaşında erkek hasta yürüyememe, impotans, idrar gayta inkontinansı şikayeti ile başvurdu. 15 yıldır şikayetlerinin mevcut olduğu ve 12 yıl önce operasyon öyküsü olduğu saptand1.. Şikayetlerinin son 1yıldır artmış olduğu görüldü. Hastanın nörolojik muayenesinde 3-4/5 pareparatik ve L1 seviyesi altında anesteziye yakın hipoestezi tespit edildi. Posterior yaklaşımla elektromonitörizasyon eşliğinde gross total tümör eksizyonu yapıldı. Postoperatif dönemde ek nönolojik defisit gelişmedi. 


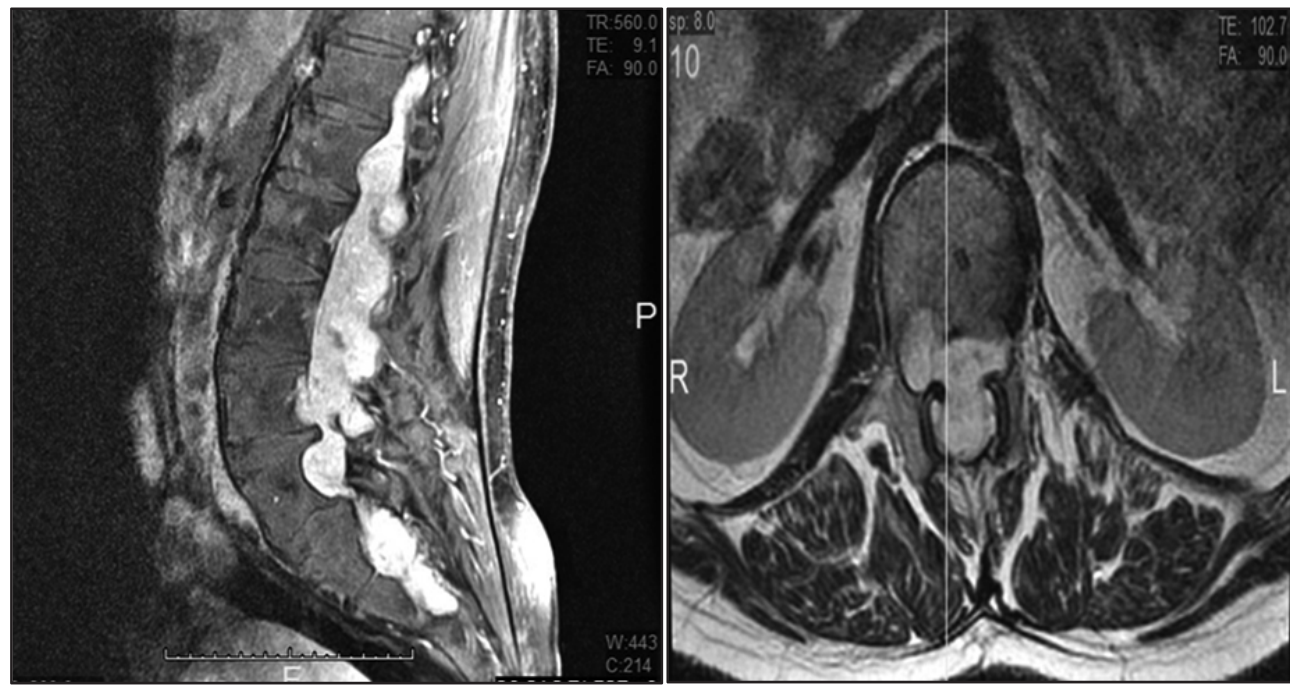

Şekil 5: 42 yaşında erkek hasta yürüyememe, impotans, idrar gayta inkontinansı şikayeti ile başvurdu. 15 yıldır şikayetlerinin mevcut olduğu ve 12 yı önce operasyon öyküsü olduğu saptandı.

\section{TARTIȘMA}

Sinir kılıfi tümörleri spinal tümörler içinde en sik rastlanılan tümörlendendir ve bunlar içinde en çok schwannomlar ve nörofibrom görülmektedir. Schwannomlar genellikle 4-5. dekatta artı̧̧ gösterirler ve erkek-kadın eşit dağılımı görülmektedir (8).

Schwannomlarin hem ekstradural hem de konus düzeyinde olması nadir görülür $(9,10)$. İlk bulgular tümörün seviyesine göre değişkenlik gösterebilir. Ağrı çoğunlukla geçici bıçak saplanır tarzdadır ve bacaklara yayılır, bazen sürekli ve tümör lokalizasyona uyan bölgede olur (7). İlerleyen dönemde sinir köklerinin irritasyonuna bağlı ağrılar ortaya çıar $(4,6)$. Daha sonraki dönemlerde omurilik hasar artışı ve myelopati gelișir (11,12). Ekstradural komponenti olan tümörlerde duyu ve motor bulgular ön plandayken, intradural tümörlerde ağr1 ön plandadir (13). Alt ekstremite güçsüzlüğü, empotans, idrar-gayta inkontinans1, duyu bozukluklar1 gibi bulgular görülebilir. $\mathrm{Bu}$ bulguların ağrisız olmasi konus medullaris sendromunu akla getirmelidir (8). Tanıda MRG önemli yer tutar. MRG de T2 kesitlerde hiperintens ve kontrastlı kesitlerde dural kuyruk olmamasiyla meningiomdan ayırt edilir (5). Schwannomların prognozu preoperatif nörolojik durumla yakındır ilgilidir. Cerrahide total eksizyon genellikle küratiftir(12,14).

Ameliyatda total eksizyon hedeflenir. Preoperatif klinik bulgular, özellikle şiddetli olmayan olduğu durumlarda iyi sonuçlar sağlar. Spinal sinir kilıfi tümörlerin total rezeksiyonu hedeftir ancak bazen bu mümkün olmamaktadir $(11,12,15,16)$. Epidural yapışıklıklar, subpial kord yapışıklıkları, kanama total rezeksiyonu engellemektedir. Ancak, çevre yapıların anotomisini iyi kavramak ve titiz mikro cerrahi teknikleri kullanmak bu engelleri aşmay1 sağlıyabilir. Rezidü tümör durumunda uzun süreli gözlem gereklidir. (17). Ameliyatta laminoplasti tercih edilmesi rezidü tümör varlığın ikinci operasyon için avantaj sağlayacaktır.

Hastalarımızın hepsi konus medullaris seviyesinde tümörü olan olgulardı. İlk geliş şikayetlerine bakıldığında üçünde bel ve bacak ağrisı mevcuttu. Hastalardan ikisinde, bu iki olguda nüks-rezidü vakalard,, nörolojik defisit mevcuttu. Bunlardan birinde de kauda equina sendromu gelişmiști. $\mathrm{Bu}$ olguların ikisi anterolateral üçü posterior yolla opere edildi. Ameliyatların tümünde elektromonitörizasyon yapıldı. Postoperatif hiçbir hastada nörolojik kötüleşme izlenmedi. 4 hastada total rezeksiyon, 1 hastada subtotal rezeksiyon sağland1.
Bizim hastalarımızdan ikisi nüks olguydu. Bunlardan birini anterolateral yaklaşımla diğerine posterior yaklaşımla operasyon yapıldı. İki monitarizasyon yapıldı ve total rezeksiyon yapildı. Postop dönemde ikisinde de ek nörolojik defisit izlenmedi. Posterior yaklaşımla opere edilen 1 hastada peroperatif elektromonitörizasyon potansiyellerinde 1srarc1 düşme nedeniyle subtotal rezeksiyon yapıldı. Ameliyat öncesi nörolojik defisiti olmayan hastada postoperatif dönemde de nörolojik defisit izlenmedi.

Uygun cerrahi yöntemin seçilmesi, uygun mikrocerrahi yöntemler ve nöromonitörizasyonun kullannılması nüks-rezidü vakalarda bile total rezeksiyona imkan sağlamıș ve nörolojik defisit gelişmesini önlemiștir. Bir vakada nöromonitörizasyon uyarısıyla subtotal çıkarilarak total rezeksiyona gidilmemiş ve böylece hastada nörolojik defisit gelişmesinin önüne geçilmiştir.

Sonuç olarak, konus seviyesi yerleșimli schwannom olgularında nöromonitörizasyon kullanımı, ek nörolojik defisitlerin engellenmesi ve daha fazla rezeksiyonun sağlanması açısından oldukça önemlidir. $\mathrm{Bu}$ olgularda nöromonitör kullanımı cerrahiyi başarıyı arttıracağ1 gibi komplikasyon riskini de minimale indirecektir. 


\section{KAYNAKLAR}

1. Van Goethem J.W.A, van den Hauwe L., Özsarlak Ö, et al. Spinal tumors. European Journal of Radiology 2004; 50: 159-176

2. Goy AMC, Pinto RS, Raghavendra BN, et al. Intramedullary spinal cord tumors: MR imaging, with emphasis on associated cysts. Radiology 1986;161:381-386.

3. Stein BM, McCormick PC: Spinal intradural tumors. Wilkins RH, Rengachary SS (edts), Neurosurgery, cilt 2A, ikinci bask1, New York: Mc Graw Hill, 1996: 1769-1781.

4. Celli P, Trillo G, Ferrante L: Spinal extradural schwannoma. J Neurosurg Spine 2005; 2: 447-456,

5. De Verdelhan O, Haegelen C, CarsinNicol B. et al. MR imaging features of spinal schwannomas and meningiomas. J Neuroradiol 2005; 32: 42-49,

6. Dorsi MJ, Belzberg AJ: Paraspinal nerve sheath tumors. Neurosurg Clin N Am 2004; 15: 217-222,

7. Jee Ho Jeon, Hyung Sik Hwang, Je Hoon Jeong, et al. Spinal Schwannoma; Analysis of 40 Cases: J Korean Neurosurg Soc 2008; 43: 135-138
8. Özdemir N, Sevin İE, Çelik L, ve ark. Conus Medullaris Sendromuna Neden Olan ve Tamamı Extradural Yerleşimli Schwannoma: Gec Donemde Opere Edilen bir Olgudaki Cerrahi Etkinlik: Türk Nöroşirürji Dergisi, 2007; 17: 2, 120-123

9. Conti P, Pansini G, Mouchaty H, et al. Spinal neuromas: Retrospective analysis and long-term outcome of 179 consecutively operated cases and review of the literature. Surg Neurol 2004; 61: $35-44$

10. Harzallah L, Boujaina E, Amara H: Low back pain and sciatica as the presenting symptoms of neurinoma near the conus medullaris. Contribution of magnetic resonance imaging. Joint Bone Spine 2005; 72: 187-189

11. Hori T, Takakura K, Sano K: Spinal neurinomas--clinical analysis of 45 surgical cases. Neurol Med Chir (Tokyo) 1984; 24: 471-477

12. Subaciute J: [Early diagnosis of spinal cord schwannoma: the significance of the pain syndrome]. Medicina (Kaunas) 2002; 38: 1086-1088
13. Jinnai T, Hoshimaru M, Koyama T: Clinical characteristics of spinal nerve sheath tumors: analysis of 149 cases. Neurosurgery 2005; 56: 510-515

14. Mathew P, Todd NV: Intradural conus and cauda equina tumours: a retrospective review of presentation, diagnosis and early outcome. J Neurol Neurosurg Psychiatry 1993; 56: 69-74

15. Conti P, Pansini G, Mouchaty H, et al. Spinal neurinomas: retrospective analysis and long-term outcome of 179 consecutively operated cases and review of the literature. Surg Neurol 2004; 61: 34-43 discussion 44

16. Lot G, George B: Cervical neuromas with extradural components: surgical management in a series of 57 patients. Neurosurgery 1997; 41: 813-820; discussion 820-822

17. Jinnai T, Koyama T: Clinical characteristics of spinal nerve sheath tumors: analysis of 149 cases. Neurosurgery 2005; 56: 510-515; discussion 510-515 
